\title{
Building a Conceptual Model for Analyzing Sustainability Projects Aiming at Technology Transfer: A Terminological Approach
}

\author{
Deise Rocha Martins dos Santos Oliveira ${ }^{1,2}$, Irenilza de Alencar Nääs ${ }^{1}$, \\ Ivo Pierozzi Júnior ${ }^{2}$, and Oduvaldo Vendrametto ${ }^{1}$ \\ ${ }^{1}$ Paulista University-UNIP, Graduate Program in Production Engineering, \\ Dr. Bacelar St. 1212, São Paulo, Brazil \\ irenilza@gmail.com, oduvaldov@uol.com.br \\ ${ }^{2}$ Embrapa Agricultural Informatics, Dr. André Tosello Avenue, 209, \\ Barão Geraldo, P.O. Box 6041, 13083-886, Campinas, SP, Brazil \\ deise.oliveira@gmail.com, ivo@cnptia.embrapa.br
}

\begin{abstract}
R\&DI institutions have adopted solutions based on Portfolio Management Project (PMP) to select the best projects in terms of both cost and strategic results. The candidate projects must meet sustainability requirements, since investments in sustainability have emerged as the most important global issue for business, industry, government, and academia. The objective of this research was to develop a conceptual model for analyzing a portfolio of sustainability projects. Such a portfolio provides descriptors widely recognized to support technology transfer, notably in the agricultural domain. This conceptual model was developed from a case study of Embrapa (Brazilian Agricultural Research Corporation). Although the proposed model has become a simple tool, the results revealed it is interesting for reclassification of the Embrapa's projects, pointing to solutions on sustainability with a potential for technology transfer.
\end{abstract}

Keywords: Portfolio Management Project, Embrapa's project portfolio, Standardized categoriation system, Agrovoc, Thesaurus.

\section{Introduction}

Every institution is subject to limited resources, either material, financial or personal. To reduce inefficient allocation of resources is essential to implement a selection process for identifying what are the projects of highest priority and value.

Institutions without clear criteria for selecting projects face high-risk investment in wrong projects. Clearly, such institution requires a rational and concrete process capable of justifying the decisions on project selection. The focus should not be just in terms of cost, but also concerning the return that such projects can offer. In doing so, some projects must be eliminated or even delayed according to the value they contribute to an institution mission [1]. 
In searching for choices that add value and justify their investments, many institutions have adopted solutions based on Portfolio Management Project (PMP). These solutions provide a repository of projects that allow for monitoring results and facilitating the capture of lessons learned from the strategic decisions taken in the past [2], besides other advantages.

In particular, R\&DI institutions have adopted solutions based on PMP not only to reduce direct and indirect costs, but also to eliminate redundant and inefficient projects [3]. The selected projects aim at providing solutions capable of encompassing technologies, products and services (TPS) designed to meet the needs of the market. The challenge, however, goes further: it is not enough to have technologies, products and services that satisfy human needs, such solutions must be sustainable across time and space, and in environmental, social and economic dimensions.

Sustainability has emerged as the most important global issue for business, industry, government, and academia. According to WCED [4], sustainable development is a process in which there is harmony between resource exploitation, the direction of investments, the orientation of technological development and institutional changes that enrich both present and future, as a potential for meet the needs and aspirations of human beings. It is inserted in all productive sectors, particularly in agriculture, which is a sector that requires attention due to the interfaces that its activities establish with environment, economy and society in general. Moreover, agriculture is the sector responsible for the production of raw materials for food, fiber and, more recently, for alternative energy.

Issues of sustainable agriculture are related to human survival. The use of land, soil and water, global climate change, food safety, vegetal and animal sanity are some of the Government concerns, but also became part of our day-to-day lives. The environmental, social and economic aspects make it clear that technologies, products and services are priorities for any program on sustainable agriculture and livestock.

The objective of this research was to develop a conceptual model that facilitates the analysis of a portfolio for sustainability projects. Such portfolio provides descriptors widely recognized to support technology transfer, notably information related to the sustainability of agricultural activities. This conceptual model was developed from a case study of Brazilian Agricultural Research Corporation (Embrapa).

\section{Methodology}

The terminological conceptual model is proposed to investigate a project's database developed by Embrapa. It is important to learn with past experiences to plan future projects, always considering the companies' mission and strategies. In this research, the aim is to reach projects focused on sustainability and technology transfer.

The proposed model is based on a theoretical referential explored in processes of documentary analysis, organization and knowledge representation. Such a model borrows some elements from the Concept Theory, the Faceted Classification Theory; the General Terminology Theory; and the Communicative Terminology Theory [5-7]. 
The proposed model assumes that all the knowledge is based in concepts which human mind organizes everything that can be understood in the real world. The concepts can be represented by words that are part of a special vocabulary, called terminologies. This model can facilitate the information recover and organization process.

To initiate this process, a user can enter terms describing the research (sustainability and technology transfer) into AGROVOC thesaurus. AGROVOC thesaurus is a terminological resource that contains over 40,000 concepts about food, nutrition, agriculture, fishery, forestry, environment and other related areas. It was developed in English and it is held by the Food and Agriculture Organization (FAO), an organization linked to the United Nations (UN) and headquartered in Rome, Italy [8]. AGROVOC is part of Agriculture Information Management Standarts (AIMS) that is a web portal managed by FAO and that disseminates standards and good practices in information management for the support of the right to food, sustainable agriculture and rural development.

A thesaurus is a system (or model) for knowledge organization and representation that evolves progressively in terms of structure and function of specialized vocabularies, and where synonyms, polysemies or associative and hierarchical relationships between terms are established according to a pattern internationally recognized [9].

Based on the keywords "sustainability" and "technology transfer", submitted to AGROVOC, we built up a list of generic terms for the agricultural domain. From those generic terms, we recovered the related terms and, subsequently, it was performed a mapping of the terms extracted. Based on these terms, a standardized categorization system is then organized to represent the best descriptors for technologies, processes or services regarding the agricultural sector. The projects are organized into a hierarchical tree [10] and the keywords retrieved from the Embrapa's project portfolio can be either submitted again for new analysis, or used to select projects whose results are related to sustainability and have potential for technology transfer. The same methodology can be used for any or different group of words. Actually, when the words are submitted to AGROVOC, it is not compulsory that they really have related words. In this case, we found some related words, and this helped us in the research.

It is important to note that, originally, the projects and the database were written in Portuguese. Portuguese is one of the 21 languages presented by AGROVOC. So, this work was done in that language. Only for this paper, we translated into English, using the terms shown by AGROVOC.

We adopted a methodology of exploratory research that, according to Gil [11], it is designed to provide an overview on a particular fact, not formulating accurate hypotheses. So, our theoretical referential was based on a literature survey comprising the domains of sustainability and technology transfer.

We performed the case study at Embrapa. In Brazil, Embrapa is an institution focused on RD \& I with a mission to provide solutions for the sustainable development of agriculture [12]. Its bibliographical asset and its project portfolio are vast, covering many different subjects. But only from late 90 's, the subject on sustainability has received a special attention. The main questions for this research were: What projects are those? What were their results? Do they still feasible nowadays? 
The case study was conducted by extracting keywords announced by the authors from Embrapa's project portfolio, which is composed of 14,736 projects, comprising the period from 1994 to 2009.

\section{Results and Discussion}

In institutions of RD \& I, the TPS are developed from research projects. In general, these institutions work with a project portfolio often designed with different logics of organization and planning. However, these portfolios rarely establish strategies a priori for transferring of the generated knowledge. If this issue is thought afterwards, it can create conflicts of interest or even technical and administrative barriers, such as those related to intellectual and industrial property, or copyright, in addition to rework to its evaluation from this point of view.

According to Cribb [13] technology transfer is understood as the displacement of technological knowledge from one place to another. According to Tigre [14], an innovation only produces comprehensive impact when it is spread widely across companies, sectors and regions, unleashing new ventures and creating new markets. Tigre also says that the dynamics of diffusion can be understood as the adoption path of a technology in the market, with focus on the characteristics of technology and other elements that influence its pace and direction.

As we mentioned previously, we performed a case study taking into account the Embrapa's project portfolio with the purpose of validating the conceptual model for analyzing sustainability projects aiming at technology transfer. The purpose is to understand what was done in the past and plan future projects for the Organization.

In this model, we assume that all knowledge is based on concepts under which the human intellect categorizes all the things that we understand in the real world. The concepts can be represented by words that make special vocabularies, called terminologies. Thus, by means of terminological resources, the proposed model aims at facilitating the recovery and reorganization of the desired information. A sketch of the proposed model is depicted in Figure 1.

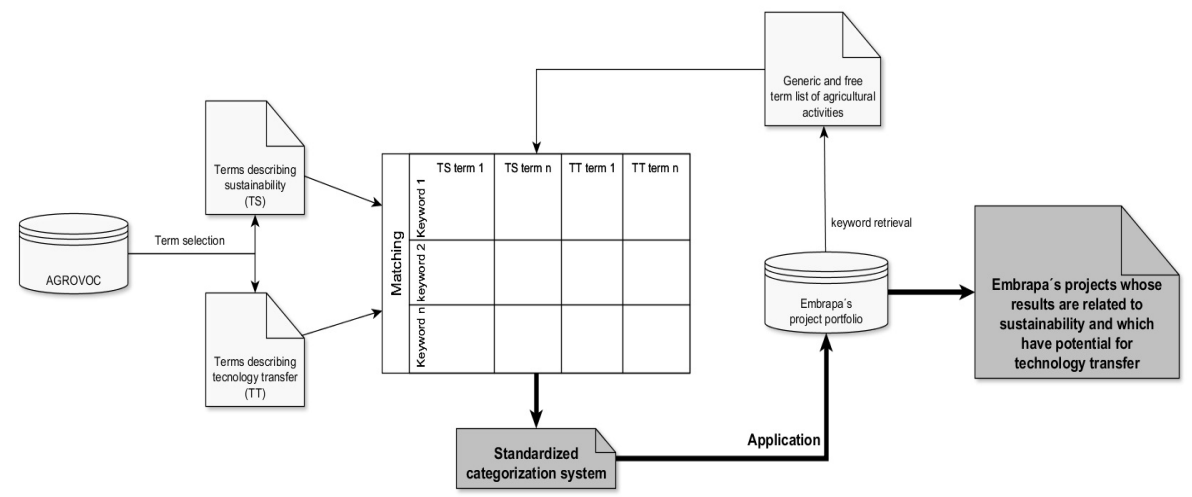

Fig. 1. A general view of the proposed model for analyzing sustainability projects

First, we entered the word "sustainability" into AGROVOC and recovered 17 related terms, as can be seen in Table 1 . 
Table 1. Related terms available at AGROVOC related to sustainability

\begin{tabular}{cl}
\hline Relationship Type* & Term \\
\hline RT & Ecology \\
RT & natural resources \\
RT & agroecosystems \\
RT & biological production \\
RT & sustainable land management \\
RT & integrated land management \\
RT & sustainable development \\
RT & balance of nature \\
RT & low input agriculture \\
RT & sustainable agriculture \\
RT & conservation tillage \\
RT & sustainable forestry \\
RT & socioeconomic development \\
RT & alternative agriculture \\
RT & farm inputs \\
RT & draught animal cultivation \\
RT & resource management \\
\hline
\end{tabular}

*Legend: Standardized relationships of a thesaurus: "used for" (UF); "broader term" (BT); "narrowed terms" (NT);"related terms"(RT).

In the next step, we then entered the term "technology transfer" into AGROVOC and found 17 related as presented in Table 2.

Table 2. Related terms available at AGROVOC related to technology transfer

\begin{tabular}{cl}
\hline Relationship Type* & Term \\
\hline UF & application of technology \\
BT & Activities \\
NT & diffusion of research \\
NT & innovation adoption \\
RT & Research \\
RT & pilot farms \\
RT & Patents \\
RT & appropriate technology \\
RT & Modernization \\
RT & diffusion of information \\
RT & digital divide \\
RT & research networks \\
RT & communication technology \\
RT & extension activities \\
RT & Innovation \\
RT & Exhibitions \\
RT & technological changes \\
\hline
\end{tabular}

*Legend: Standardized relationships of a thesaurus: "used for" (UF); "broader term" (BT); "narrowed terms" (NT); "related terms" (RT). 
Subsequently, it was performed a mapping of the terms extracted from texts of the projects with those consulted on AGROVOC, building up a specific system for categorization to represent the best descriptors related to sustainability and technology transfer.

As a result, we found 581 projects having the term sustainability and 611 projects containing the term technology transfer. In the next step, we searched for the terms sustainability and technology transfer together into the Embrapa's project portfolio and found 44 projects, which represents only $0.3 \%$ of the total $(14,736)$.

Through the model application, it was possible to explore a certain term. For instance, from the term sustainability, 17 keywords were generated, and other 17 words were generate for the term technology transfer, enhanced the input of a search system to retrieve information.

\section{Conclusions}

In this work we proposed a conceptual model for analyzing sustainability projects aiming at technology transfer for institutions of R\&DI. We performed a case study by using the Embrapa's project portfolio to validate the model.

We summarize the main results of the case study at Embrapa, as follows:

- Major of the projects were developed without criteria that are relevant at the present time. So we need to find different ways to extract knowledge from the Embrapa's project portfolio;

- This conceptual model can be used with any group of words, and not only with sustainability or technology transfer;

- The historical context at Embrapa has not prioritized issues of sustainability and technology transfer. Such issues have received special attention since the 90's.

- The model is simple, flexible, and can be easily adapted to other R\&DI institutions.

We believe that this model can be easily adapted to meet the requirements of solutions based on Portfolio Management Project (PMP) in institutions of R\&DI. As a continuation of this work, we are now analyzing the proposed model, considering both efficiency (use of resources) and effectiveness (achieving positive results for the organization) issues, and also analyzing their risks.

\section{References}

1. Cooper, R.G., Edgett, S.J., Kleinschmidt, E.J.: Portfolio management for new products. Perseus Books (1998)

2. Levine, H.A.: Project Portfolio Management: A Practical Guide to Selecting Projects, Managing Portfolios, and Maximizing Benefits (Jossey-Bass Business \& Management). John Wiley \& Sons (2005)

3. Martino, J.P.: R\&D project selection. John Wiley \& Sons (1995) 
4. WCED. Our Common Future. The World Commission on Environment and Development, p. 400. Oxford Univ. Press, Oxford (1987)

5. Bufrem, L.S., Gabriel Jr., R.F.: The appropriation of concept as an object in the scientific periodical literature in information science. Inf. 16(esp), 52-91 (2011)

6. de Campos, M.L.: Documentary language: theories underlying their preparation. EDUFF, Niterói (2001) (in Portuguese)

7. Carlan, E., Medeiros, M.B.B.B.: Systems of Knowledge Organization in view of Information Science. RICI: R.Ibero-amer. Ci. Inf. 4(2), 53-73 (2011) (in Portuguese)

8. Agrovoc (2012), http://aims. fao.org/website/AGROVOC-Thesaurus/sub

9. Zeng, M.L.: Knowledge organization systems (KOS). Knowledge Organization 35(2-3), 160-182 (2008)

10. Lévy, P., Authier, M.: The knowledge trees. Editora Escuta, São Paulo (1995) (in Portuguese)

11. Gil, A.C.: Methods and techniques of social research. Atlas, São Paulo (1999) (in Portuguese)

12. Embrapa, http://www. embrapa.br

13. Cribb, A.Y.: Determinants of technology transfer in the Brazilian agribusiness food: identification and characterization. Journal of Technology Management \& Innovation 4(3) (2009) (in Portuguese)

14. Tigre, P.B.: Innovation management: the economics of technology in Brazil. Elsevier, Rio de Janeiro (2006) 